\title{
A cultura de brincar de boi-bumbá
}

\section{The Culture of Playing Boi-Bumbá}

Nádia Tobias de Souza Seara é pedagoga com especialização em Psicopedagogia pelo Instituto de Ensino Superior Martha FalcãoAM e em Educação Lúdica em contextos escolares não formais e corporativos, no Instituto Superior de Educação Vera Cruz (ISEVEC). Desenvolve pesquisa sobre o imaginário simbólico e a cultura de brincar de boi-bumbá em Parintins, Amazonas e faz fotografia.

Contato: nadiaseara@uol.com.br

\section{Resumo}

0 presente artigo é um recorte de um dos capítulos que compõem a pesquisa Devaneios poéticos e a cultura de brincar de boi-bumbá em Parintins-AM, que constitui uma espécie de topofilia - uma intelecção de quem nutre pelo seu rincão imenso sentimento amoroso. A ação é descritiva e subjetiva; emprega-se em sua narrativa a poética do devaneio sobre a cultura do brincar de boi-bumbá dos povos da floresta (índios, caboclos e nordestinos). A pesquisa foi realizada durante as últimas semanas que antecederam o megafestival folclórico de Parintins-AM. Destaca-se o olhar sensível para a cultura de brincar de boi-bumbá dos povos da floresta, nas figuras dos tarefeiros, participantes, integrantes, moradores, apreciadores e brincantes dos Bois-Bumbás: Caprichoso e o Garantido. A fenomenologia de Gaston Bachelard entrelaça toda a pesquisa, que tem como objetivo reexaminar, por meio de um novo olhar, imagens do brincar, ou seja, encontrar por trás das imagens que se mostram, as imagens que se ocultam: a iminência do imaginário no real e o movimento do real ao imaginário. A fundamentação bibliográfica contempla, no tocante ao Amazonas, Marcio Souza; a Parintins, Rodrigues; a outros olhares, Ferreira-Santos e Paes Loureiro. A motivação do trabalho foi, ao mesmo tempo, a constatação do pouco cuidado que a população tem com a memória cultural, 
material e imaterial, e a manutenção orgulhosa da tradição que une elementos indígenas, caboclos e a presença sutil de uma educação de sensibilidade.

Palavras-chave: boi-bumbá; cultura; devaneios poéticos.

\section{Abstract}

This paper leans back to one of the chapters of Devaneios Poéticos e a cultura de brincar de boi-bumbá which is some sort of topophilia - an expression of huge love affection for some place. The narrative is descriptive and subjective, using a poetic daydream over the culture of playing boi-bumbá for the rain forest people (índios, caboclos and nordestinos). The research was made during the prior weeks of the "Parintins folclore festival", enlightening the sensitive outlook over the culture of playing boi-bumbá presented by the local people who works and plays toward Caprichoso and Garantido Boi Bumbás. The phenomenology of Gaston Bachelard lays in all the research which main scope is to verify images of playing boi-bumbá culture through new eyes, seeing the hidden images behind the pictures, mixing reality and imagination. The bibliography contemplates Marcio Souza, from Amazonia, Rodrigues from Parintins and different outlooks provided by Ferreira Santos and Paes Loureiro. The motivation to do the research came from the observation of the low level of cares provided by people over the material and immaterial cultural memory and at the same time the pride of keeping alive the culture that holds together native elements and the keen presence of a sensitive education. Key words: Boi-bumbá; culture; poetic daydream.

Este artigo recorta um dos capítulos que compõem a pesquisa Devaneios poéticos e a cultura de brincar de boi-bumbá em Parintins-AM que representa uma busca pessoal por novas experiências, num entrelaçamento de cultura dentro de culturas: um processo de criação, de corporificação de ideias, da gestação ao parto: "criar é dar existência ao que não existia antes - como qualquer parto, a concepção começa no corpo" (Murray, 1992, p. 138).

Adotei uma ação descritiva e subjetiva para ser fiel às minhas imagens primordiais: "é exatamente este exercício difícil de relativizar nossos valores, cosmovisões, regras morais e sociais [...], para compreender - em profundidade - a emergência da 
outra pessoa" (Ferreira-Santos, 2002, p.18). No exercício de relativizar, deu-se o entrelaçamento de olhares de Bachelard, Ferreira-Santos, Marcio Souza, Paes Loureiro, entre outros. Gaston Bachelard, viga mestra da pesquisa, vê

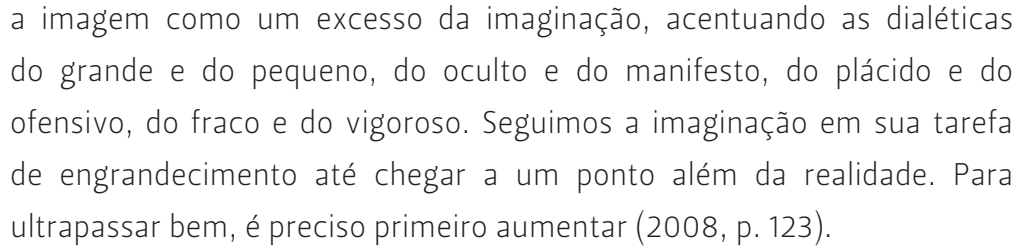

A pesquisa tem como objetivo reexaminar, com um novo olhar, imagens do brincar de boi, ou seja, encontrar por trás de imagens que se mostram, imagens que se ocultam: a iminência do imaginário no real e o movimento do real ao imaginário. 0 trabalho objetiva também cavoucar a raiz da cultura de brincar de boibumbá.

Campo de pesquisa: Parintins, berço criativo dos Bumbás - Caprichoso (fundado pelos irmãos Cid, em 1913) e Garantido (fundado por Lindolfo Monteverde, em1920). A ilha localiza-se a $400 \mathrm{~km}$ de Manaus. A sua história acomoda fatos de superação e glória. Gozou das benesses do período áureo da borracha; acolheu a anima japonesa no período Vargas, conquistando, com a produção da juta, projeção nacional. Com a Segunda Guerra, tudo virou espólio. Desse tempo, pouco restou, gerando certo descaso com a memória cultural material e imaterial local.

A abordagem: um exercício de observar o outro na sua alteridade, pela acolhida e pelo respeito à sua subjetividade. Os encontros deram-se nos ensaios da festa, nos bares, nos restaurantes, nas praças, nos currais. 0 pervagar em terras alheias fomentava um quiasma cultural. Esse aproximar-se pelos olhos, nos quais o intangível se acomoda no instante em que eles, silenciosos, são permissivos e tornam o invisível, visível: "apalpando-o com o olhar, coisas que não poderíamos sonhar ver 'inteiramente nuas', porquanto o próprio olhar as envolve e as veste com sua carne." (Merleau-Ponty, 2005, p. 128).

\section{Parintins: Ilha Tupinambarana}

0 canteiro germinal de criação do imaginário tem o céu como uma grande abóboda, mantendo a atmosfera encantada da ilha. Se eu fosse criar uma representação simbólica de seus moradores, eles se transfigurariam: seriam metade homens, metade alegorias imaginárias, de tão fértil para as imagens é esse lugar: "cada poeta 
nos deve, pois, seu convite à viagem. Por esse convite recebemos, em nosso íntimo, um doce impulso [...] (Bachelard, 2001, p. 4).

Nessa incursão, não pretendo esgotar o imaginário simbólico da cultura de brincar de boi-bumbá, apenas procuro lançar uma luz sobre ele; não pretendo "cegar com tanta luz [...], tanta fé na razão [...]; são divagações tateantes," (Ferreira-Santos, 2002, p. 148) e alguns pensamentos teóricos sobre cultura e culturas: "o conhecimento (antropológico) da nossa cultura passa [...] pelo conhecimento das outras culturas; e devemos especialmente reconhecer que somos uma cultura possível entre tantas outras." (Laplantine, 2007, p. 21). Sigo minhas imagens primevas e entro no mítico processo de criação e cultura de brincar de boi-bumbá em Parintins.

É um procedimento que exigiu o olhar orgânico do conhecer os outros na respiração, transpiração, na cópula, usando um termo durandiano - na sua corporeidade, no seu campo de criação, gesticulação - "na sístole/diástole cardíaca." (Ferreira-Santos, 2002 , p. 142). Lançar um olhar de sensibilidade às diferenças pluriculturais e históricas contidas nesse universo lúdico foi o desejo por trás de meu trabalho.

Tal pluralidade cultural "abre uma janela" para se pensar imaginariamente uma teia de valores, crenças, cheiros, costumes, hábitos, falas, saberes, gestos, fazeres. A ideia de teia é uma instigação ao aprofundamento, ao mergulho no universo caboclo miscigenado e rico. Ela é um convite a viver nuanças: "poder viver uma nuança nova diante de um espetáculo que convida à uniformidade que se resume numa ideia" (Bachelard, 2008, p. 207/208).

Assumo, como Geertz, "cultura como sendo essas teias e a sua análise, portanto, não como uma ciência experimental em busca de leis; mas como uma ciência interpretativa, à procura de significados"(2008, p. 4). Essa analogia com a teia também cria uma imagem de acolhimento; lembra rede, balaio, pandeiro, o tipiti, objetos estes moldados por mãos habilidosas, olhares atentos. Penso cultura e culturas, dentro desse pluralismo de significados. No caso, a cultura dos brincantes e tarefeiros de boibumbá. Essa mistura de índios, negros, nordestinos traz vestígios do velho continente para compor a miscelânea brincante. Daí se pode entender o que foi dito anteriormente: o conhecimento da nossa cultura passa inevitavelmente pelo conhecimento das outras culturas. 
Há, entretanto, uma preocupação latente em não criar propostas inovadoras: "qualquer proposta de uma teoria geral a respeito de qualquer coisa social soa cada vez mais vazia" (Geertz, 2008 , p. 4). Sentir-me revolucionada auxiliava-me a ressignificar a tessitura desta teia-narrativa. Em terras tupinambaranas, reacendo a ideia da jornada interpretativa.

Foi necessário ficar fora para fazer o caminho de volta, com um olhar de geógrafo, de viajante e de romancista para reconstruir conhecimentos do meu interior e do interior do mundo parintinense, e partir para um reencontro com as vozes dos tarefeiros, brincantes que se deixam levar pela manifestação explícita de suas anima e seus animus.

"Parintins, viver e amar," como lembram os outdoors da Prefeitura Municipal. 0 tempo nem parece ser sequencial; ele se torna efêmero, profícuo como o tempo do poeta, do canto, do amor. Tempo propício do fantasiar, do germinar na llha Tupinambarana. Onde é o limite? Não há limites; há novos desafios, muita imaginação e devaneios poéticos. "A imagem poética terá a sonoridade do ser. 0 poeta fala no limiar do ser" (Bachelard, 2008, p. 2). Em Parintins, os poetas, os tarefeiros do boi-bumbá transitam no limiar da criatividade do ser. As imagens vêm como produto fecundado no coração da alma. Esse potencial criativo é externado durante as três noites de brincadeira, dança e espetáculo na arena do bumbódromo.

Em Parintins, assim como em todo Amazonas, o imaginário do povo assumiu uma potência criadora e mágica, que faz as culturas transitarem entre mundos - o real, o imaginário simbólico e o mítico - como nos mostra a cosmogonia do povo parintintim. "0 devaneio poético nos dá o mundo dos mundos. 0 devaneio poético é um devaneio cósmico" (Bachelard, 2006, p. 13).

\section{0 mito de criação da Ilha de Parintins}

Os sinos estão debaixo da terra. Os índios revoltados com a invasão dos missionários jesuítas, em suas terras, amotinaramse e destruíram a missão. A igreja foi depredada; soterraram seus sinos e fugiram para matas distantes. Tudo aconteceu à meia-noite do dia 25 de dezembro... "Meia-noite... todos ouviram 12 badaladas ensurdecedoras, vindas de cima da serra, cujos ecos se perdiam na vastidão das matas, vindas talvez ou certamente de um sino de bronze de proporções gigantesca" (Saunier, 1989, p. 6). 
0 escritor e poeta Tonzinho Saunier - homem noturno -, que não se deixou transformar, traz em sua obra um olhar expansivo para o povo parintintim, que nos faz olhar embevecido para esse espaço íntimo que é a Ilha Tupinambarana: "Os poetas nos ajudarão a descobrir em nós uma alegria tão expansiva de contemplar que às vezes, diante de um objeto próximo, viveremos o engrandecimento do nosso espaço íntimo" (Bachelard, 2008, p. 204).

Toda essa construção mítica da localidade comunga com os pensamentos da fenomenologia bachelardiana, quando afirma que as imagens se constroem em nossos pensamentos muito antes de a alma percebê-los e, quando nos damos conta, já estamos aderentes a eles: "até os dias de hoje, enfim, para o viajante que vem de fora, contemplar a Amazônia exige deles um verdadeiro ritual: desejo intenso, ideias, planejamento, recursos financeiros, tempo, motivação, ato de presença para contemplar e vivê-la" (Loureiro, 2001, p. 70-71).

Os aventureiros, exploradores, admiradores, pesquisadores e amantes da natureza continuam chegando e pasmam-se diante do potencial natural e simbólico do homem e natureza amazônida.

A igreja ocupou-se, nas invasões, da usurpação espiritual e cultural. 0 escritor Márcio Souza diz que "aquele foi o momento em que a região teve "seu universo pluricultural e mítico devassado e destruído, desmontado pela catequese e pela violência" (Souza, 2001, p. 54).

A constatação da presença jesuítica parece reforçar a narrativa mítica ligada à insurreição dos índios contra a missão evangelizadora. No ano de 1796, "surge além-mar, o capitão de milícia José Pedro Cordovil com seus escravos e agregados que em nome da coroa portuguesa ocuparam a aldeia violentamente." (Andrade, s/d, p. 3). Cordovil teria se deparado com a etnia Tupinambá, oriunda do litoral brasileiro. Os tupinambás - povo hostil - por sua vez hostilizavam os nativos da ilha e outras etnias que dividiam o território - os sapupés e maués - originando confrontos e o êxodo dos parintintins, que migraram para a região do Rio Madeira, atualmente conhecida como Humaitá, berço acolhedor de alguns índios parintintim.

Em "30 de outubro de 1880, pela lei provisória $n^{\circ} 499$, a sede do município recebeu foros de cidade e passa a chamar-se Parintins" (Rodrigues, 2006, p.31). A ilha recebia, assim, uma deferência para com antigos habitantes da região, os índios parintintins. No 
passado, dois produtos projetaram a ilha no cenário comercial: a borracha, que trouxe riqueza, poder e desenvolvimento às capitais - Manaus e Belém. A Ilha Tupinambarana, pela sua localização geográfica privilegiada, gozava de um efervescente comércio ribeirinho de produtos extrativistas da floresta, pesca e pecuária.

Parintins soube usufruir das benesses do ciclo da borracha que oportunizou o desenvolvimento que a levaria a ser palco de uma ousada ocupação, desta vez pacífica, mas imbuída de interesses políticos, ideológicos. Filhos de outros orientes se preparavam para chegar. Segundo Rodrigues, "271 koutakusseis se instalariam numa localidade chamada Vila Baptista, mas tarde renomeada de Vila Amazônia" (2006, p.42).

Do apogeu ao marasmo, após a decadência da borracha e da juta, Parintins reergueu-se novamente com um festival. No Festival Folclórico de Parintins, espetáculo de sublime beleza, no qual pode ser contemplado, além das lendas e tradições locais, todo o talento e criatividade do homem do Amazonas, o ritmo da toadas é contagiante.

\section{O Festival de Parintins}

Da praça digital pode-se observar que a romaria das águas começa: o movimento de barcos é significativo. 0 rio acolhe-os, transfigurados de "brincante" aquático. Poucos barcos buscarão outros destinos: a maioria ficará para a festa. Fogos anunciam sua chegada, o volume de objetos, mercadorias que saem do seu interior transformam-se em um espetáculo à parte, o movimento é rápido e intenso.

Os passageiros em solo estão transmutados. Não são mais pecuaristas, pescadores, agricultores... São brincantes de boibumbá, costureiros, artesãos, bordadeiras, pessoas simples, tranquilas. Coincidentemente, na atualidade, a pecuária é uma das principais atividades econômicas do município, que é um dos maiores produtores bovinos e bubalinos do estado.

Eles serão estrelas ou corações que brilharão na arena do bumbódromo, num grande espetáculo teatral a céu aberto. 0 bumbódromo tem uma arquitetura exótica: seu formato - visto do alto - lembra a cabeça de boi. Dentro dessa megaestrutura, cumpre-se a promessa de mais um ano de raça, emoção e tradição. 
A cidade é simples, aconchegante como seu povo. Olhando-a mais detidamente, percebe-se a presença de antigos casarões. Sua arquitetura, no geral, lembra um provincianismo esquecido no tempo: "diante de um mundo tranquilo, na planície tranquilizadora, o homem pode conhecer a paz e o repouso" (Bachelard, 2008, p. 212). Há poucas construções contemporâneas; nenhuma exibe um design arrojado. Os raros sinais de modernidade vêm de algumas residências particulares, que se destacam das demais. Curiosamente, a maioria das casas é pintada com as cores dos bois preferidos. São fachadas, jogos de terraços, entre outros detalhes, dando a cidade tons em branco e vermelho, branco e azul.

A cidade tenta se organizar para atender ao público dentro das suas modestas acomodações de acolhimento. Tenta acolher com responsabilidade uma demanda crescente de caboclos "parentes" - expressão usada pelas pessoas no contato social, uma espécie de gíria urbana com "bicho", "brother", "velho", "rapaz" (Rodrigues, 2006, p. 36) -, brasileiros e estrangeiros que, ano após ano, vêm participar do megafestival em que se transformou a brincadeira de boi-bumbá. Contudo, não se percebem grandes investimentos ou melhorias que potencializem a cidade em função do turismo local. O Festival Folclórico potencializa a cidade por apenas três efervescentes dias.

As agremiações dos Bois-Bumbás têm a nítida noção do potencial financeiro, turístico e de desenvolvimento da cidade. Só que, onde o dinheiro sobeja, sobejam também problemas de ordem administrativa. Por enquanto, vamos acreditando nos binômios cultura-cabocla e folclore popular, uma manifestação popular autêntica, pois busca a forma clássica, faz a releitura de uma das mais enraizadas danças populares: o boi-bumbá.

Como em todas as cidades do interior, as noites são iluminadas pelas fogueiras; há festas por todos os recantos: arraiais, missas na catedral, praças iluminadas, shows com cantores locais, barracas de comidas típicas, de produtos artesanais, acessórios indígenas...

Conhecer os parintinenses na sua subjetividade, preservando um olhar zeloso sobre sua alteridade, no seu modo de se constituir enquanto amazônida, aquele que, entre outras coisas, abandona seu rincão para se aventurar no ritmo das toadas do boi do coração; ter sabedoria para "clarear" a vista diante de depoimentos como o do ex-tripa do Boi Garantido, conhecido pela alcunha de Patinho: "Quando ouço as batidas dos tambores, largo tudo e venho pra cá, brincar no meu boi da minha infância". Arredondando esse pensamento bachelardiano, acrescentamos: "a 
infância dura a vida inteira. É ela que vem animar amplos setores da vida adulta" (Bachelard, 2006, p. 20).

0 respeito à alteridade visual dos "atores" da pesquisa foi ponto fundamental neste trabalho, que contou com o suporte da fotografia: "o uso da imagem na cultura popular considera lícita a transformação de certos momentos da vida, certas situações em imagens fotográficas" (Martins, 2009, p. 16).

A presença real dentro do processo de pesquisa: "o etnógrafo perturba determinadas situações com sua presença e é, ao mesmo tempo, perturbado por essa situação. 0 que o pesquisador vive em relação com seus interlocutores é parte da sua pesquisa" (Friedmann, 2009, p. 8). É delicado esse processo de estar presente dentro do campo de pesquisa. De qualquer sorte, perturbamos e somos perturbados, não temos como ficar alheios; somos parte do todo também.

Agindo assim, a relação com os interlocutores na prática ocorreu de forma tranquila. Às vezes, a sensação era a de transitar livremente na dualidade dos mundos. Foi "preciso substituir um pensamento que isola e separa por um pensamento que distingue e une" (Morin, 2008, p. 89).

Não havia um pensamento isolante, e sim um que unia o próprio folguedo. Alguns moradores usufruem desse período prosperamente, pois estão envolvidos com o festival por meio do comércio de variadas modalidades: hotéis, pousadas, balneários, restaurantes, magazines. Outros são ex-brincantes, portanto, acolhem o turista com simpatia; são extrovertidos e abertos a horas de conversa. Sem nenhum demérito, apenas fazendo uma ressalva: permeando este fazer, há questões políticas e interesses econômicos.

Na contramão dessa efervescência vêm os abusos, o desrespeito que deixam um rastro de incompreensão de/em ambas as partes. 0 reflexo dessa desrespeitosa conduta favorece um olhar desvirtuado sobre as jovens meninas que, muitas vezes, transformam-se em mães solteiras. 0 risco ronda a tranquilidade e a integridade física e emocional das crianças menores. Na tentativa de alertar e coibir, é veiculada uma campanha de conscientização junto ao público infanto-juvenil, pais, responsáveis e turistas. São olhares de fora para dentro, de quem faz uma leitura deturpada da docilidade e ingenuidade dessa população: "seria banal lembrar que a criação e a destruição são elementos conjuntos de toda estruturação social" (Morin, 2008, p. 120). 
No geral, o povo é muito receptivo, carinhoso; também sabe ser arisco, arredio, precisando de tempo para se abrir, para conhecer e se acostumar com a nossa presença, o nosso jeito de falar, de observar, de nos achegarmos. Superado esse momento - pronto! -, somos todos da mesma tribo: "é dessa ousadia, dessa coragem, eu diria dessa abertura, que depende a harmonia societal" (Maffessoli, 2005, p. 131).

Conforme afirma Merleau Ponty (2005, p. 128),

não há, portanto, coisas idênticas a si mesmas, que, em seguida, se oferecem a quem vê, não há um vidente, primeiramente vazio, que em seguida se abre para elas, mas sim algo de que não poderíamos aproximar-nos mais a não ser apalpando-o com o olhar, coisas que não poderíamos sonhar ver "inteiramente nuas", porquanto o próprio olhar as envolve e as veste com sua carne.

Dialogar com o mundo noturno instigante de Bachelard, deixando nos seduzir pelo universo dos devaneios, da fenomenologia, da sensibilidade, da estesia, da poética, dos elementos e imagens de um determinado grupo cultural e suas manifestações simbólicas é explicitamente excitante. Vivenciar a arte de brincar junto a formas alquímicas vivas, colhidas em meio ao teatro-arena a céu aberto, foi sem dúvida, um especial presente.

\section{Os Bumbás}

\section{Garantido:}

A origem dos Bumbás é prosaica e cercada do imaginário popular, assim como dos mistérios, das encantarias e das lendas amazônicas. No livro 0 Magnífico Folclore de Parintins, de Tonzinho Saunier, há uma entrevista de Lindolfo Monteverde, fundador do Garantido, concedida ao autor, então repórter. Lindolfo ratifica que a brincadeira de criança transformou-se em manifestação folclórica a partir de 1920.

O nome dado ao boi de pano perpassa a mesma linha narrativa prosaica e misteriosa. 0 nome Garantido teria surgido de um encontro com o delegado de polícia e os irmãos Lindolfo e Amâncio durante o registro policial para inibir as brigas, fato muito comum durante as incursões bumbalinas nas ruas de Parintins e em Manaus. 
A determinação de Lindolfo trouxe tradição e certo alento para a população pobre da baixa de São José, bairro da periferia de Parintins, onde nasceu. 0 reduto é atualmente do "boi do povão", "brinquedo de São José", "boi do coração" e "eterno campeão", ou simplesmente "Garantido". Esses são os slogans herdados pelo boi branco da baixada.

Figuras históricas e tradicionais também se corporificaram ao folguedo bubalino, mas só Lindolfo ganha o respeitoso título de "mito folclórico", uma homenagem a um homem simbólico, lúdico e noturno, que, durante muitos anos, idealizou, produziu, apresentou seu brinquedo de São João na rua. Conta sua filha Maria do Carmo, em uma entrevista, que "foi com a voz de veludo que Lindolfo conquistou sua mãe [...]. Ele cantou para a bela morena: 'acorda morena bela vem ver, meu boi serenando no terreiro, assim mesmo ele faz lá na fazenda quando avista o vaqueiro...".

O vermelho e branco são as cores dessa paixão. É curiosa essa devoção/paixão pelo Garantido, como no caso de uma ex-madrinha do Garantido, que tem a sua casa à beira do rio Amazonas como um espaço sagrado. Há "recortes" do passado em todo canto, parede, dentro ou fora. Um ambiente rubro de paixão.

De acordo com Rodrigues (2006, p. 68),

\footnotetext{
O lugar onde morreu Lindolfo serviu por muitos anos como local de ensaios do bumbá Garantido, mas, a partir do ano de 2000, as atividades passaram a ser realizadas na Cidade Garantidas. Porém, o velho terreiro ainda tem o status de Curral Antológico, sendo utilizado todos os anos no dia 24 de junho, dia dedicado a São João Batista, quando acontece uma ladainha para pagar a promessa feita pelo fundador do boi ao santo de sua devoção.
}

\section{Caprichoso:}

O Boi Caprichoso também tem uma história prosaica, rica em detalhes, cujas versões se desencontram. Raimundo Cid e Pedro Cid, quando chegaram a Parintins, vindos da cidade do Crato, Fortaleza, fizeram uma promessa ao santo de sua devoção: queriam prosperidade. Em troca, enquanto vidas tivessem, levariam às ruas a brincadeira de boi-bumbá. A folclorista Odneia Andrade, residente em Parintins, confirma a data de 1913 para a fundação, reforçando os méritos da criação do Caprichoso pelos irmãos Cid. A administração do Boi Caprichoso também passou por várias famílias. Num processo crescente, aos poucos, a brincadeira de boi-bumbá foi perdendo a inocência dos tempos de seu surgimento para ganhar fôlego de megaespetáculo. Mas tal 
intrepidez não passou despercebida aos olhos dos seus adeptos e do povo.

A folclorista Odneia Andrade esboça, em sua entrevista, certa preocupação com a nova geração de potenciais dirigentes. Preocupada, enquanto pesquisadora e folclorista, tem um olhar atento para as raízes. Tal posição nem sempre é apreciada ou entendida pelos mais jovens, talvez pela falta de vínculos com a cultura local, pelo deslumbramento do que vem de fora para dentro, de forma descontextualizada.

Ela valoriza a sabedoria dos antigos, da velha guarda, cujas histórias são ricas fontes de múltiplos elementos do cotidiano. Para alguns jovens há um grande descaso com essa memória cultural material e imaterial. "Touro Negro da América", "Boi da Inovação", "Boi da estrela na testa" são outros tantos slogans pelos quais o "Boi Caprichoso" é conhecido.

0 boi-bumbá de Parintins traz, na sua essência, a força da matéria terrestre, ao longo dos 46 anos de festival. 0 real potencializa suas imagens imaginadas, visíveis em suas produções, pois são imagens que brotam de cada tarefeiro responsável pelas alegorias e pelos grupos de fantasias: "quando o real se faz presente, com toda a sua força, com toda a sua matéria terrestre, pode-se crer que a sua função descarta a do irreal". (Bachelard, 2008 , p. 3). E, em parte, o enredo tem ainda a responsabilidade de seguir o roteiro da brincadeira nos moldes tradicionais.

Segundo Saunier (1989, p.34),
Em 1965 iniciou-se o Festival Folclórico organizado. O criador foi o senhor Raimundo Muniz Rodrigues que juntamente com Xisto Pereira, Lucinor Barros e o Reverendo Padre Augusto, em reunião na sede da JAC (Juventude Alegre Católica), lançaram as bases daquela que seria um dos maiores festivais do gênero, no Brasil. Neste ano, os bumbás se apresentaram na JAC, mas não houve competição.

0 ponto alto da brincadeira em Parintins, em cada uma das três noites, é a confraternização - linda, lúdica, divertida - entre as raças: o branco, o negro e o índio. As potências criadoras e reprodutoras dos caboclos tarefeiros do boi transformam a união num belo espetáculo cênico, dançante, dramático e vibrante. Numa característica tipicamente regional, destaca-se a presença da cultura indígena, representada pelas diversas tribos femininas e masculinas, pelos tuxauas-luxo, a batida ritmada das toadas e a grande apoteose. 0 folguedo deriva da tradição espanhola e 
da portuguesa, "[...] tradição de se encenarem peças religiosas e folclóricas de inspiração erudita, mas destinadas ao povo para comemorar festas católicas nascida na luta da igreja contra o paganismo" (Coelho, s/d).

O homem moderno vai buscar nas tradições religiosas e místicas das tribos indígenas matéria para libertar suas imagens imaginadas. Como visto, esse tempo festivo tem características e elementos caboclos, que justificam o diferencial da brincadeira de boi-bumbá na Amazônia. Os personagens de maior destaque são as mulheres: a cunhã-poranga - mulher mais bela da tribo, a sinhazinha, filha do dono da fazenda, assim como outras figuras femininas caracterizadas por sua beleza estética. Lembro a presença majoritariamente feminina na brincadeira de boi-bumbá: foi a mulher a primeira a cultivar as plantas alimentares. Foi ela que, naturalmente, se tornou proprietária do solo e das colheitas [...]: a figura da Mãe-Terra, a floresta, a Amazônia.

Destacam-se também as figuras masculinas: o pajé (curandeiro), e outros personagens cativantes, entre eles as tribos masculinas, os tuxauas, o levantador de toadas e o amo do boi. Nas suas origens, a brincadeira contava com os seguintes personagens: os brincantes das Marujadas (Caprichoso) ou das Batucadas (Garantido), índios, pinto-piroca, bicho-folharal, neguinho do campo grande. Aos poucos, o boi inovação trouxe outros personagens, como Dona Aurora e o Gigante.

Ao estilo show business (midiático), a inclusão de novos itens femininos tornou-se imprescindível. De um modesto festival feito para alegrar a juventude de Parintins, hoje o evento faz a alegria de mais de 40 mil espectadores, segundo dados da Secretaria de Cultura do Estado do Amazonas. A luxúria social estrangulou a "pureza" dos festivais originais, organizados pela JAC (Juventude Alegre Católica). Os festivais interioranos caminharam da pureza daqueles ocorridos nas ruas de Parintins sob a luz dos lamparineiros - carregadores de lamparinas -, ao exótico festival folclórico para o mundo ver. Criação e quebra de paradigmas: "o contraditorial em ação: a sociedade une e, ao mesmo tempo, se revela cruel." (Maffesoli, 2005, p.121). 0 boi espetáculo, como muitos dizem, ganhou seu espaço na mídia, despertou interesses políticos e garantiu espaço nos cofres públicos.

Creio que um olhar mais atento, uma visão "fontana", a buscar na fonte primordial a água fresca, é o que Odneia vem fazendo ao tentar trazer à luz pensamentos críticos, reflexivos. É um começo para suscitar o processo de resgate dessa cultura material e 
imaterial ligada às tradições, tão relegada ao segundo plano pelos mais jovens. Odneia Andrade, professora aposentada, tem essa visão e busca essa "fonte" quando nos fala dos seus projetos. Um deles, intitulado "Oh que delícia de rua", é um trabalho de formiguinha que, pensado para escolas públicas de Parintins, tem o objetivo de resgatar o "boi tradição" e outras brincadeiras não originárias da cidade, mas manifestações lúdicas e folclóricas. Há pontos em comum com o olhar da pesquisadora. Compartilhamos inspirações e desejos, prefigurando o início de um relacionamento de ideias. Compartilhar sonhos e desejos... Quando isso não ocorre, é sinal de que a morte simbólica dos sonhos e desejos não tardará.

0 ritmo da festa segue na percussão dos toques das palminhas, das caixinhas, do surdo, bem regional. Acrescentaram-se ao remodelamento dos ritmos, o xarango, o violão, o banjo regional, o teclado, o contrabaixo, a guitarra, para sofisticar a musicalidade. Toda essa mudança instrumental deu-se em função da evolução das toadas. Tais toadas, legítimas representantes musicais do Amazonas, perderam a versão nordestina dos repentes para um estilo melódico mais regional, com características próprias. São aproximadamente 35.000 fantasias produzidas para as três noites de festival e algo em torno de 2.500 brincantes. A temática gira em torno de temas tribais, caboclos, folclóricos e amazônicos - com grafismos étnicos, elementos da fauna e da flora:

De acordo com o Guia (2007, p. 161),

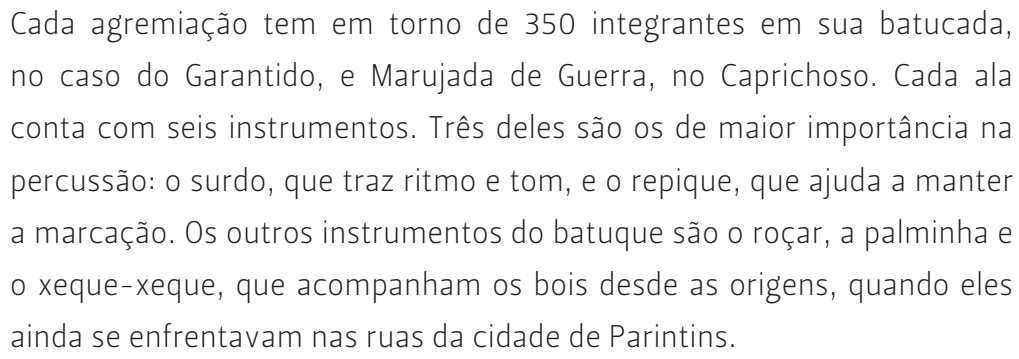

Eis uma breve descrição dos chamados itens, na versão atual do boi-bumbá, como figuras de pontuação para os bumbás:

Amo do boi: personagem tradicional de autos de boi-bumbás espalhados pelo Brasil; é o dono da fazenda e do boi.

Apresentador: personagem que conduz todo o espetáculo; atua como mestre de cerimônias, introduzindo todos os itens, contando a história do boi e o tema que será abordado.

Boi-bumbá: personagem principal da brincadeira em todo o país, motivo e "razão de ser" do festival, o boi marca a rivalidade 
nas cores e nos símbolos.

Cunhã poranga: a índia mais linda da tribo, em língua tupi, representa a forma da beleza indígena presente na Amazônia.

Lamparineiros e bailado corrido: figuras típicas do início do boibumbá; não contam pontos como itens de avaliação, mas estão sempre presentes nas apresentações.

Levantador de toadas: é a voz do Boi que canta todas as toadas durante as três noites.

Batucada e marujada de guerra: assim se denominam, respectivamente, os agrupamentos de percussão do Garantido e do Caprichoso. Cada um deles, composto por mais de 400 participantes.

Pajé: no tradicional auto do boi-bumbá, o curandeiro é chamando à fazenda para salvar o boi doente. É um dos personagens mais performáticos e místicos.

Porta-estandarte: personagem que se apresenta como índia e representa a diversidade cultural do boi-bumbá.

Rainha do folclore: personagem indígena, que remete às manifestações folclóricas. Aparece no momento da alegoria, figura típica regional.

Sinhazinha da fazenda: filha do amo, loira e de cabelos cacheados, usa um vestido comprido e rodado, luvas finas e uma delicada sombrinha, sendo inspirada nas antigas sinhás.

Tribos: personagens coletivas representando, a cada noite, algumas das etnias indígenas.

Tuxauas: autoridade máxima da tribo, o tuxaua é o grande chefe que resolve conflitos, orienta a comunidade, convoca reuniões e hospeda visitantes da aldeia.

Vaqueirada: personagens coletivos tradicionais do boi-bumbá em todo o Brasil. Durante o Festival, o grupo de vaqueiros é encarregado, pelo amo da fazenda, de proteger o Boi.

Por hora, deixo que a imaginação do leitor seja seduzida por uma curiosidade de quem olha por uma fresta da teia, uma parte mínima da brincadeira e se deixe levar pela imaginação: "a experiência corporal e as imagens do cérebro são um único processo com duas expressões" (Keleman, 1999, p. 104). 
0 trabalho é inconclusivo. Será preciso lançar e colher sementes no kepos fértil parintinense, espaço para imagens criadoras e reprodutoras. Arvoro-me a dizer que o processo de manutenção orgulhosa do imaginário caboclo, da cultura, da tradição, perpassa uma educação de sensibilidade, presente na figura dos iniciadores - tarefeiros - que sabem mostrar o leito do rio, fora mesmo dos muros das escolas. Em terra tupinambarana, brincar de boibumbá é ver nascer, das mãos habilidosas dos mestres- tarefeiros, motivos para imaginar e projetar cenas futuras.

\section{REFERÊNCIAS}

ANDRADE, Odneia. Parintins: pinceladas de sua história: acervo pessoal. s/d.

BACHELARD, Gaston. O ar e os sonhos: ensaio sobre a imaginação do movimento. São Paulo: Martins Fontes, 2001.

2006.

A Poética do Devaneio. São Paulo: Martins Fontes,

A Terra e os devaneios da vontade: e outros ensaios sobre a imaginação das forças. São Paulo: Martins Fontes, 2008.

FERREIRA-SANTOS, Marcos. A cultura das culturas: Mytho e Antropologia da Educação. Cad. Educ. Fa/EJUFP, Pelotas, RJ, n. 18, p. 135-152, jan.-jun. 2002.

FRIEDMANN, Adriana. Antropologia da Infância. Apostila curso ISEVEC, 2009.

GREERTZ, Clifford. A interpretação das culturas. Rio de Janeiro: LTC, 2008.

GUIA, Turismo. Parintins: ecologia, história e cultural. Empresa das Artes, 2007.

KELEMAN, Stanley. Mito e Corpo: uma conversa com Joseph Campbell. São Paulo: Summus, 1999.

LAPLANTINE. François. Aprender Antropologia. São Paulo: Brasiliense, 2007. 
LOUREIRO, João de Jesus Paes. Cultura amazônica: uma poética do imaginário. São Paulo: Escrituras, 2001.

MAFFESOLI, Michel. A sombra de Dionísio: contribuição a uma sociologia da orgía. São Paulo: Zouk, 2005.

MARTINS, José de Souza. Sociologia da fotografia e da imagem. São Paulo: Contexto. 2009.

MERLEAU-PONTY, Maurice. O Visível e o Invisível. São Paulo: Perspectiva, 2005.

MURRAY, Louis. Dentro da dança. Rio de Janeiro: Nova Fronteira, 1992.

RODRIGUES, Allan. Boi-Bumbá evolução - livro-reportagem sobre o Festival folclórico de Parintins. Manaus: Editora Valer, 2006.

SAUNIER, Tonzinho. Magnífico Folclore de Parintins. Manaus: Empresa Oficial. 1989.

SOUZA, Márcio. Breve história do Amazônia: a incrível história de uma região ameaçada contada com o apaixonado conhecimento de causa de um nativo. $2^{a}$ edição, Rio de Janeiro: Agir, 2001.

Recebido em fevereiro de 2012 Aprovado em março de 2012 